\title{
A GEOGRAFIA E SUA PERTINÊNCIA PARA O ESTUDO DA DIVERSIDADE CULTURAL - UM TERRITÓRIO CIGANO
}

\author{
Ademir Divino Vaz ${ }^{1}$
}

\begin{abstract}
Resumo: Nas últimas décadas a Geografia vem lançando novos olhares sobre as questões que se referem aos processos sócio-culturais como a construção de identidade, as vivências culturais, os diferentes modos de ser e agir que os diversos grupos sociais constroem no espaço. Este artigo apresenta um diálogo sobre a Geografia Cultural e seu referencial para a diversidade cultural apresentando um estudo realizado com uma Comunidade Cigana em Ipameri, Sudeste de Goiás. É propósito compreender os diferentes elementos que constituem a formação de um território e a territorialização do grupo na cidade. A leitura dessa realidade sob a ótica da Geografia Cultural e os métodos de trabalho propostos por ela foram os suportes metodológicos para a execução da Pesquisa.
\end{abstract}

Palavras-chave: Geografia; Diversidade Cultural; Ciganos; Território.

\section{Introdução}

Desde os anos setenta do século passado, vem se configurando, no quadro da produção geográfica, um horizonte denominado humanista cultural. Essa corrente tem se destacado a partir da ação e do interesse de geógrafos que têm refletido sobre as várias dimensões da ciência geográfica.

Um novo olhar é lançado sobre as questões que se referem aos processos sócio-culturais como a construção de identidade, as vivências culturais, os diferentes modos de ser e agir que os diversos grupos sociais constroem no interior das classes, as múltiplas relações e significações que os sujeitos estabelecem no seu espaço.

A representação espacial significa para a geografia humanista cultural, segundo GOMES (1996), mais do que uma indicação da localização dos fenômenos. Por meio dela é possivel resgatar a inteligibilidade que os fatos espaciais adquirem quando são interpretados a partir de seus contextos próprios. Para este autor, quando os grupos humanos se organizam espacialmente, nem sempre têm consciência explícita de todos os processos de significação que são atribuídos e vividos cotidianamente no espaço. Assim, cabe também ao geógrafo, interpretar todo o jogo complexo de analogias, de valores, de representações e de identidades que figuram neste espaço

Admite-se que essa corrente epistemológica visa analisar de que modo os fatores culturais e de percepção interferem nas ações de organização e elaboração do espaço geográfico. Assim, esse espaço resulta não apenas das transformações econômicas, mas também das condições psicológicas e físicas dos indivíduos e das sociedades, sobretudo da experiência de vida de cada pessoa e das heranças culturais coletivas.
A construção do conteúdo humanista cultural fez a Geografia buscar aporte teórico-metodológico em outras ciências, como na filosofia, na antropologia, na sociologia e outras, para melhor compreensão do espaço geográfico. As concepções metodológicas adotadas fundamentaram-se, principalmente, em pressupostos filosóficos da fenomenologia. Esses pressupostos, segundo BUTTIMER (1982), propõem para o estudo da geografia a análise dos espaços humanizados enquanto regiões culturais, domínios étnicos, territoriais, etc; espaços diferenciados segundo as disposições subjetivas dos homens-habitantes. Para a autora, os pressupostos apelaram por descrições mais concretas tanto do espaço e do tempo quanto de suas significações no dia a dia da vida humana.

Sobre a fenomenologia, entende-se como uma alternativa de reflexão em relação à construção do conhecimento. Nesta abordagem, o espaço geográfico é tratado como o espaço social e dos horizontes sociais da experiência humana, os quais se manifestam nos processos de interação social e organização desse espaço.

\section{A Geografia e seu referencial para a diversidade cultural}

Aliada a esse horizonte humanista, a Geografia Cultural se fortalece e se dedica a rediscutir os conceitos da geografia e sua presença na evolução do pensamento geográfico desde meados do século XIX. PAUL CLAVAL (1999), em sua obra La Géographie Culturelle, destaca que o termo geografia cultural foi introduzido pela primeira vez na Alemanha por Friedrich Ratzel na década de 1880. Ratzel dedicou-se ao estudo dos fundamentos culturais da diferenciação regional da Terra reconhecendo nos povos a mobilidade como um atributo de sua essência.

${ }_{1}$ Professor Mestre do curso de Geografia da Universidade Estadual de Goiás. e-mail: ad.vaz@bol.com.br 
As contribuições para a Geografia Cultural na segunda metade do século XIX e na primeira metade do século XX, mesmo sendo abordagens parciais, foram importantes e fazem parte da evolução de um pensamento cultural na Geografia.

Devido à intensificação da industrialização e conseqüentemente, com o desenvolvimento técnico, em particular das comunicações, a Geografia Cultural entra em "crise" e a cultura passa a estar relacionada às grandes cidades e às áreas industrializadas. Para CLAVAL (1999) e GOMES (1996), a renovação da Geografia Cultural vem, a partir dos anos 1970, permeada pelo horizonte humanista na ciência geográfica. Esta revalorização ocorreu em um momento em que a contestação aos modelos de ciência, baseados na univocidade da razão lógica estariam sendo fortemente questionados.

Através dos seus conceitos-chave, a Geografia passa a valorizar a cultura segundo sua dimensão simbólica. As experiências vividas, o conhecimento adquirido, as assimilações coletivas dão significado à sociedade e evocam a Geografia Cultural. Assim, a Geografia vai desenvolvendo-se enquanto ciência social e aperfeiçoando seus conceitos e temas, numa postura em que 0 homem deve responder não apenas às excitações que emanam da natureza, mas, sobretudo, ao papel cultural do homem como agente essencial na transformação do espaço.

Este olhar espacial precisa dar conta de perceber e reconhecer os mecanismos que movem as pessoas e as coisas todas dos lugares; para verificar e compreender as dinâmicas que se estabelecem. E acima de tudo, conseguir verificar que são os homens que geram esses movimentos todos, e que pela sua força e capacidade de organização e de condução dos seus destinos, terão influências maiores ou menores advindas da natureza, das decisões políticas, dos interesses econômicos e sobretudo culturais.

Assim sendo, a Geografia assume compromissos maiores com a sociedade e cabe ao geógrafo, dentro de seus padrões sociais e morais, procurar empregar o seu saber primordialmente na procura de soluções dos problemas da sociedade. Se a Geografia tem compromissos para com a sociedade, ela deve ser uma ciência libertadora para todos os povos, deve ser um conhecimento vivo que conduz à descoberta do universo, da vida e do homem.

Acredita-se que é função da Geografia pensar 0 estabelecimento de relações através da interdependência, da conexão de fenômenos, numa ligação entre o sujeito humano e os objetos de seu interesse. É preciso o estudo da territorialização de muitos grupos humanos, negando a idéia de uma sociedade pronta, em que todos os problemas já estejam resolvidos. 0 mundo atual traz com enorme velocidade as transformações ante as quais é inútil a simples análise da aparência. Cabe à Geografia a análise do real, revelando as causas e efeitos, a intensidade, a heterogeneidade e o contexto espacial dos fenômenos que configuram cada sociedade, mostrando que esses fenômenos são produtos das relações que orientam 0 cotidiano das pessoas, definindo seu lugar e $o$ interligando a outros conjuntos espaciais.

Portanto, a Geografia deve reconhecer as contradições e os conflitos econômicos, sociais e culturais. Só assim torna-se uma ciência do presente, inspirada na realidade contemporânea, entendendo o mundo atual e a apropriação dos lugares pelo homem. Desta forma, parcelas discriminadas da sociedade, podem ter a Geografia como aliada, sendo uma ciência também dos excluídos. Por isso, acredita-se que a Geografia deve ser uma ciência comprometida com todo o povo, com a maioria e com a minoria, sem segregação étnica e, deve preocupar-se em fazer uma análise mais humana dos homens, procurando entender seus sentimentos, seus hábitos e seus valores.

Dentre os membros do grupo considerado "minoria", que na verdade é maioria, encontram-se os Povos Ciganos que fazem parte da massa de despossuídos e excluídos. Esses povos são segregados há vários séculos pelo mundo. É sobre um grupo cigano na cidade de Ipameri, a sudeste de Goiás, que se desenvolveu este trabalho no período de 2000 a 2003.

\section{A Construção do Território Cigano}

Para a execução da pesquisa foram realizadas várias visitas ao local de estudo para estreitar os vínculos entre a fundamentação teórica do projeto e o conhecimento empírico dos ciganos. Na primeira visita, foram apresentados os objetivos da pesquisa com o intuito de ampliar o apoio da comunidade cigana. As visitas permitiram participação junto ao cotidiano dos ciganos, para obter respostas aos objetivos.

0 método de pesquisa proposto pela corrente teóricometodológica da Geografia Cultural respaldou-se em autores como HAESBAERT (1995 e 1999), SOUZA (1995), CLAVAL (1999), RATZEL (1982) e outros, os quais trabalharam as relações entre grupos sociais e $o$ território, segundo a perspectiva cultural.

0 trabalho de gabinete constituiu-se em atividades relacionadas ao levantamento de informações em fontes secundárias e leituras de bibliografias clássicas referentes à corrente teórico-metodológica escolhida. Também foi indis- 
pensável o uso daquelas referentes à temática da pesquisa sobre os ciganos. Documentos da Prefeitura Municipal de Ipameri e do Cartório do $2^{\circ}$ Ofício de Notas de Ipameri também contribuíram na construção do conhecimento. Nessa etapa, a revisão bibliográfica permitiu a compreensão de elementos explicativos da territorialização dos ciganos em Ipameri. Simultaneamente contribuiu para elaboração dos roteiros de entrevistas e questionários a serem aplicados na pesquisa de campo.

No Território Cigano, visitas e entrevistas foram realizadas com as famílias ali residentes. O roteiro de entrevista foi respondido oralmente por um representante de cada moradia. Nele, buscou-se informações referentes à identificação do cigano e de sua família, à faixa etária, ao grau de escolaridade, ao tipo de moradia, à origem e raízes culturais, às atividades econômicas, ao relacionamento com os demais ciganos do Território e com os demais moradores da cidade, à gestão e às perspectivas com o Território.

A História Oral permitiu uma interpretação da realidade através das conversas com os ciganos sobre a experiência e a memória individual e ainda por meio do impacto que estas tiveram na vida de cada cigano. Ela foi um importante recurso metodológico na compreensão do Território Cigano. Permitiu perceber os valores culturais dos ciganos, adquiridos ao longo da vida, forneceu um perfil sobre a realidade e o cotidiano dos mesmos e de suas relações entre si e com os demais moradores na cidade.

Não se preocupou só com a descrição simples da forma do território, mas também com os significados e as práticas sociais ali presentes. Tampouco interessou sua geometria e sim as relações sociais, conflitos, usos e contextos sob os quais esta forma de território existe e resiste em tempos diversos.

Para considerar que os ciganos construíram um Território em Ipameri, fez-se a interpretação do Território enquanto um dos conceitos-chave da geografia baseando-se em HAESBAERT (1995 e 1999), MORAES (2000), RATZEL (1982), RAFFESTIN (1993) e SOUZA (1995). Parte-se de uma compreensão do território sob um prisma mais subjetivo, de um espaço no qual o homem estabelece vínculos, constrói sua história e concretiza suas relações e fatos sociais. A noção de território para o principal objeto de pesquisa, o agrupamento cigano de Ipameri, permeia as raízes culturais e históricas da família, as relações humanas e sociais no agrupamento, enfim, a organização dos ciganos na área ocupada.

Posto assim entende-se a importância e a presença do território para um grupo social, conforme mostra FRIEDRICH
RATZEL (1844-1904). Este, um dos mais importantes representantes da Escola Clássica Alemã de Geografia, em sua obra "Le Sol, la Societé et L'État" (1898), já destacava que uma sociedade sem território é irrepresentável, e que o homem não podia ser estudado como se ele tivesse se formado no ar, sem laços com a terra. Tanto o homem considerado isolado, quanto os que vivem em grupo encontrarão algum pedaço de terra que pertence ou a sua pessoa ou ao grupo do qual ele faz parte. Para Ratzel, sob variações diversas, a relação da sociedade com 0 solo permanece sempre condicionada por uma dupla neces-sidade: a da habitação e a da alimentação. Quanto mais sólido se torna o vínculo através do qual a alimentação e a moradia prendem ao território, tanto mais se impõe à sociedade a necessidade de manter a propriedade do seu território. Para 0 autor, não se pode considerar sociedade alguma sem território. A sociedade está enraizada com muita profundidade no seu território. Para ele, ao examinar o homem, seja individualmente ou associado, é sempre necessário considerar, junto com o indivíduo ou com o grupo em questão, também uma porção do território e os organismos que fazem parte do grupo, que só podem ser concebidos junto com seu território. SOUZA (1995) também reforça que um grupo não pode mais ser compreendido sem o seu território, no sentido de que a identidade sócio-cultural das pessoas estaria inarredavelmente ligada aos atributos do espaço concreto.

RAFFESTIN (1993) afirma que o território se forma a partir do espaço. Ele é o resultado de uma ação conduzida por um ator sintagmático, que realiza um programa, em qualquer nível. Ao se apropriar de um espaço, concreta ou abstratamente (por exemplo, pela representação) 0 ator "territorializa" o espaço.

Qualquer projeto no espaço, conforme este autor,é expresso por uma representação que revela a imagem desejada de um território de um local de relações. SANTOS (2002), baseando-se em Raffestin, diz que o espaço representado pressupõe a imagem de um local de relações, porque produzir uma representação do espaço já é uma forma de apropriação e de controle. Qualquer projeto no espaço que é expresso por uma representação revela a imagem desejada de um território, de um local de relações. Conforme a autora, a relação dos grupos étnicos com o espaço se configura no território visto, imaginado e construído de acordo com a realidade momentânea de cada grupamento étnico. Ela define o território para os ciganos como um espaço geograficamente delimitado, porém não juridicamente reconhecido, conferindo-lhes apenas uma categoria situacional, isto é, ligada a uma ocupação limitada no tempo, flutuante $e$ profundamente enraizada na organização do grupo. 
O território cigano em estudo está localizado na zona urbana do município de Ipameri, região sudeste do Estado de Goiás. Instalado nessa cidade, o território cigano é formado por uma comunidade, supostamente do grupo Kalon, que há décadas transitou por Ipameri. A área atualmente ocupada foi doada aos ciganos no final da década de 1990.

\section{Transitando por Ipameri}

Com o nome originário do idioma tupi-guarani, cujo significado é Entre Rios, Ipameri limita-se ao norte com o município de Cristalina; a noroeste com Orizona e Urutaí; a oeste com Caldas Novas; a Sudoeste com Corumbaíba; ao sul com Goiandira e Nova Aurora; a sudeste com Catalão; a nordeste com Campo Alegre de Goiás e parte de Cristalina. Ipameri pertence à chamada região da Estrada de Ferro, composta pelos trechos da antiga Estrada de Ferro Goiás, servindo Anápolis, Goiânia e Brasília, conectada à Estrada de Ferro Mogiana, atravessando 0 Triângulo Mineiro, até Campinas no Estado de São Paulo (Fig. 01).

No início do século $X X$, com o desenvolvimento da industrialização, o papel da ferrovia se ampliaria, passando também a orientar-se no sentido dos centros consumidores e fornecedores de matéria-prima e de excedentes alimentícios. As ferrovias imprimiram mudanças na organização espacial. Atingindo as cidades, que sofreram transformações imediatas em sua urbanização. Esse processo se intensificou à medida que as ferrovias se estenderam para 0 interior do país, conjugadas às frentes pioneiras, inserindo novas áreas na economia de mercado e levando o povoamento para várias regiões.

Segundo FERREIRA (1999), apesar de todos os percalços ocorridos no período entre 1915 e 1940, a Estrada de Ferro Goiás manteve uma certa regularidade nos serviços de transportes. Nesse período, 0 autor ressalta o saldo positivo da Estrada também em seus resultados na organização da região sudeste de Goiás e nos movimentos migratórios para a Região.

A partir da segunda década do século XX, com a implantação da Estrada de Ferro Goiás, intensificou-se a vinda de imigrantes para o município de Ipameri. Num primeiro momento, vieram os portugueses Morgados que trabalharam inicialmente na construção do leito da Estrada de Ferro e depois, dedicaram-se à agricultura e à pecuária. Posteriormente, também se radicaram em Ipameri, alemães, italianos e sírios. Assim, durante a primeira metade do século XX, a cidade passou por uma época de expressiva riqueza e efervescência cultural, como uma cidade agrícola-industrial e entreposto comercial, sustentado princi- palmente pela ferrovia, como reforça FERREIRA (1999).

Durante a primeira metade do século $X X$, conforme já mencionado, a ferrovia constituiu-se em fator fundamental para a cidade de Ipameri, em razão de ser a sua sustentação econômica e o centro das atividades locais. Sabe-se que a ferrovia era uma grande porta de comunicação entre as populações das cidades situadas ao longo dos trilhos.

As estradas, em grande parte do Estado de Goiás, antecederam a ferrovia, porém foram multiplicadas pela necessidade de se alcançar os terminais ferroviários. Na região sudeste do Estado não foi diferente, várias estradas foram construídas na primeira metade do século XX e eram usadas pelos carros de bois, tropas e transportes rodoviários (FERREIRA, 1999). Provavelmente o desenvolvimento econômico, gerado pela Estrada de Ferro Goiás, em Ipameri, teve importante papel no processo de mobilidade dos ciganos para essa cidade. Sr. José Soares da Costa, líder da comunidade cigana, nascido em 1940, na cidade de Vianópolis (localizada a $130 \mathrm{~km}$ de distância de Ipameri) e sua esposa, Dona Tereza, também nascida no mesmo ano e cidade, lembram-se de transitarem com seus pais em tropas de cavalos e posteriormente em carroças, pelos municípios cortados pela Estrada de Ferro Goiás e de permanecerem por um tempo maior no município de Ipameri. Segundo Dona Tereza, seus filhos nasceram nesse período de deslocamentos, nas cidades de Ipameri e Pires do Rio. De acordo com o censo realizado na comunidade cigana, os filhos do Sr. José e de Dona Tereza (Zélia, Jesus, Célio, Paulo, lonice) nasceram nas décadas de 1960 e 1970.

Os últimos anos da primeira metade do século $X X$ e as décadas seguintes estão representadas subjetivamente no arranjo territorial da comunidade cigana de Ipameri, ou seja, são momentos que se fazem presentes na vida dos ciganos adultos $\mathrm{e}$ são expostos oralmente como se pode ver nos depoimentos a seguir:

Antes de parar em Ipameri, nóis passamos por aqui (...). Nóis somo daqui. Eu sou daqui, de Vianópolis. Era acostumado pousar aqui, muitos anos, uns 40 anos já. Uns 40 anos nóis acampava aqui. A gente saía de tropas, de cargueiro, andava pelas estradas, pelas roças, quaise não tinha asfalto. No início não tinha carroça e não tinha perigo, não tinha assaltante (José, 62 anos - 08/01/2003). 


\section{LOCALIZAÇÃO DO MUNICÍPIO DE IPAMERI - GOIÁS}
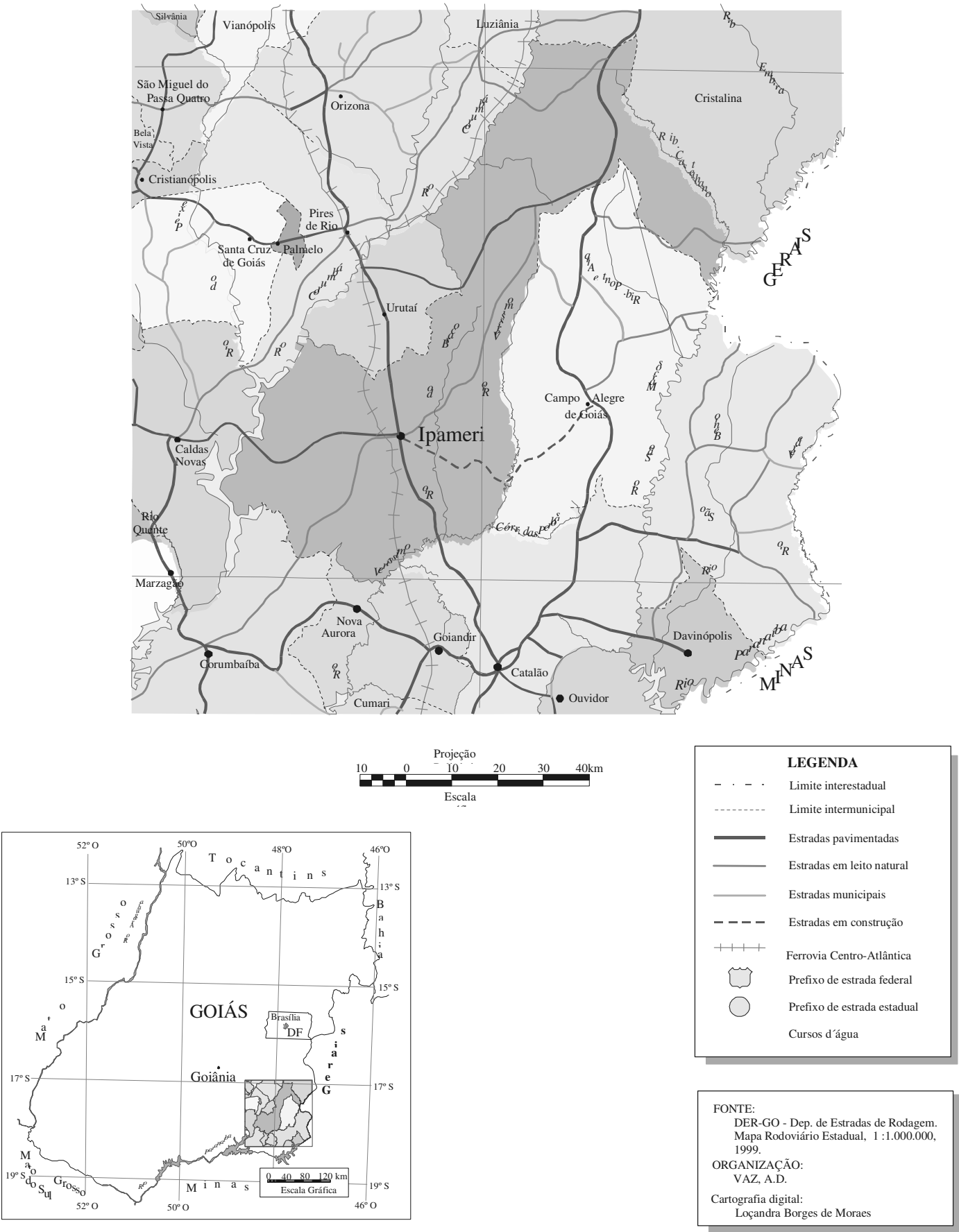

Figura 1 Localização do município de Ipameri, Goiás. 
A mulher cigana também relembra das primeiras passagens em Ipameri.

Eu também nasci em Vianópolis, eu mais ele (referindo-se a José). Antigamente tinha a turca véia, a finada Catarina, lá do outro lado. Lá era um mangueiral, ali nóis embarracava lá, de dentro lá. Eles era muito bão pra nóis. As primeiras veize que nóis passou por Ipameri, nóis ficava lá nesse lugar (Tereza, 62 anos 08/01/2003).

Nos depoimentos dos ciganos observa-se que os espaços percorridos por eles estão presentes em suas experiências de vida. LIMA (1996) destaca que: os caminhos/lugares vivenciados ciganamente aparecem com toda a força de expressão, registrados indelevelmente nas faces, nos corpos, nos olhares. No fundo dos olhos, os ciganos trazem paisagens interiorizadas nas profundidades dos seus espíritos, vindos à luz por intermédio de experiências e percepções exteriorizadas em atitudes, condutas e emoções (1996:76).

Sr. José e Dona Tereza, que são primos primeiros - o pai do Sr. José (Levino) é irmão do pai de Dona Tereza (José Pinto) tiveram conhecimento sobre Ipameri no início dos anos 60 do século passado, através de contatos com moradores da cidade por intermédio dos acampamentos ou, como diz Dona Tereza, "embarracamentos". O que é também lembrado por moradores de Ipameri que tiveram contatos com os ciganos nas primeiras décadas da segunda metade do século XX. É o caso da família do Sr. José Evangelista Troncha, que conheceu os ciganos na década de 1960.

Em 1964, nós tivemos o primeiro contato, pois meu pai mexia com olaria, e sempre traziam aqueles animais para o meu pai. Porque naquela ocasião a olaria era tocada com pipa, os animais é que puxavam a pipa para fazerem os tijolos. Em 19640 contato foi com os pais e posteriormente com o Zé e os irmãos. A amizade foi aumentando e até hoje nossa relação é muito grande (José Evangelista Troncha - 30/01/2003).

A família do Sr. José e de Dona Tereza transitou por cidades da região através de caravanas que iam pelos campos, numa vida de aventura dependendo da boa vontade de vários fazendeiros para armarem seus acampamentos. Nem todos os proprietários davam-lhes guarida e proteção. Quando a estadia era na cidade, os homens e algumas mulheres circulavam pela mesma para fazerem, de acordo com o feitio de sua gente, barganhas principalmente de mulas e cavalos.

Após vários contatos com os ciganos foi possivel conhecer e desvendar as representações simbólicas dos ciganos e reforçar a afirmação de que a identidade do Território Cigano em Ipameri é construída através da somatória das representações simbólicas dos Ciganos e das relações estabelecidas entre eles. É o significado dessas relações que dará à terra ocupada um valor não só econômico, mas também simbólico, um sentido de lugar, 0 que será apresentado na seqüência.

Os ciganos começaram a "legitimar" sua territorialização em Ipameri no final da década de 1980 quando os membros da família do Sr. José e Dona Tereza resolveram ocupar uma área dentro do perímetro urbano de Ipameri, próxima à Escola Estadual Monsenhor Domingos Pinto de Figueiredo - Polivalente, no bairro Monte Castelo.

Ficamos lá embaixo perto do Colégio Polivalente. Lá foi o primeiro lugar [refere-se a lugar "fixo"]. Ficamos lá muito tempo, que ano é aquele Tereza? [Tereza não se lembra]. Nóis ficamos lá 8 anos. De lá viemos para ali, ao lado, um terreno livre e depois pra cá. Lembra da primeira veiz que o Valfredo foi prefeito? Pois é, desde daquela veiz, a gente morava lá embaixo (Sr. José, 62 anos - 12/10/2002).

O líder atual da comunidade, Sr. José, sua esposa, Dona Tereza e o ipamerino José Evangelista Troncha foram os precursores no processo de territorialização da família em Ipameri. Os mais jovens disseram que acompanharam o Sr. José e a Dona Tereza e destacaram como dificuldade o meio de transporte para realizarem suas mudanças e como vantagem por ficarem em Ipameri, a conquista da área. Já os precursores afirmam que o contato com Ipameri há vários anos, as amizades que possuem na cidade e as ajudas que sempre receberam dos moradores foram os motivos de ficarem em Ipameri.

Onde nóis parou mesmo foi aqui (refere-se a Ipameri). Aqui a gente tinha e tem mais amizade, o povo daqui é bão, é mais conhecido (Sr. José, 62 anos - 15/03/2002).

Dona Aparecida, irmã de Dona Tereza, reforça as amizades que possuem na cidade como um dos fatores de sua permanência em Ipameri.

A nossa família tudo é nascida e criada aqui e em Pires do Rio. Eu gosto daqui. Aqui é um lugar bão e sossegado, um 
pessoal bão, nóis tudo tem amizade já com o pessoal da cidade. Todo mundo é conhecido. Minha vontade é não sair daqui (Aparecida, 57 anos - 23/01/2003).

0 bom relacionamento entre ciganos e não ciganos em Ipameri é destacado como causa da territorialização deles na cidade, de acordo com o doador da atual área.

O contato com vários moradores de Ipameri é um fator da permanência deles (...). O povo da cidade é bom pra eles. Eles compram até fiado em algumas farmácias e mercados. 0 relacionamento entre ciganos e não-ciganos em Ipameri é muito bom (José Evangelista Troncha, morador de Ipameri 30/01/2003).

Durante a permanência na área localizada no Bairro Monte Castelo, os ciganos moraram em barracas em um local muito pequeno e com vários vizinhos, entre eles um colégio que funcionava na época nos turnos matutino e vespertino. $O$ lote pertencia à Prefeitura Municipal e não tinha nenhuma infraestrutura. Nas barracas os ciganos não tinham banheiros, usavam-se privadas precárias sem quaisquer cuidados com a saúde. A falta de higiene acabou gerando várias denúncias por parte dos vizinhos e, principalmente, dos professores da Escola Monsenhor Domingos Pinto de Figueiredo.

Neste período, os ciganos começaram a manter contatos com alguns políticos da cidade, principalmente com 0 então vereador José Evangelista Troncha, que já os conhecia desde a década de 1960, conforme antes mencionado. Através desse contato, os ciganos fizeram vários pedidos ao vereador e aos prefeitos da época para conseguirem uma área para eles. Em 1998 o pedido quase foi concretizado, quando o prefeito Valfredo Perfeito, em seu segundo mandato, por intermédio do vereador, doou uma área aos ciganos próxima ao atual território do agrupamento. 0 sonho de ter um local próprio durou poucos dias, já que 0 então promotor público da cidade de Ipameri, que tinha alguns lotes vizinhos à área doada, entrou com uma ação contra a Prefeitura e exigiu que 0 vereador e 0 prefeito retirassem os ciganos em 72 horas. Sem lugar para levá-los, o senhor vereador comprou um terreno próximo ao local do despejo e os levou para a nova área.

Assim, a construção do Território Cigano em Ipameri, teve continuidade em 1999, quando eles obtiveram a doação da área pelo Sr. José Evangelista Troncha.

Relacionado com a formação do território está a territorialidade da comunidade cigana em Ipameri. A formação de um território, para ANDRADE (1994), dá às pessoas que nele habitam a consciência de sua participação, provocando 0 sentimento de territorialidade que, de forma subjetiva, cria uma consciência de confraternização entre as mesmas. Para ele, a expressão territorialidade pode ser encarada tanto como o que se encontra no território e está sujeito à gestão do mesmo, como, ao mesmo tempo, ao processo subjetivo da conscientização da população de fazer parte de um território, de integrar o território.

Também para CARA (1994), o território é uma objetivação multidimensional da apropriação social do espaço. A territorialidade é a qualidade subjetiva do grupo social ou do indivíduo que lhe permite, com base em imagens, representações e projetos, tomar consciência de seu espaço de vida.

Portanto, acredita-se que o espaço ocupado pelos ciganos reflete todo um re(arranjo) espacial e a formação de uma territorialidade que apresenta uma referência básica que é a consolidação do espaço vivido, construído a partir da percepção do grupo cigano.

O território está situado na periferia da área urbana no setor Tolentino 2, ocupando parte da rua José Ribeiro Marques e rua SR-8, é uma área de $1.738 \mathrm{~m}^{2}$ dividida em 14 lotes e mais 01 lote de $240 \mathrm{~m}^{2}$. Nas proximidades há residências e vários lotes sem construções. A área é denominada, pelos moradores de Ipameri, como saída para Goiânia, devido a sua localização próxima à GO330.

Acredita-se que os ciganos de Ipameri produzam territórios delimitados por fatores subjetivos e existenciais formados por elementos de seu cotidiano como relação de parentesco, festas e outros compromissos sociais e políticos, trabalho e ócio, dentre outros. Esses elementos estão profundamente enraizados na organização social do grupo cigano de Ipameri e obedecem a um dado ordenamento sócio-econômico-cultural respondendo funcionalmente a uma sociabilidade vigente. A moradia, o agrupamento, a cidade de Ipameri, são espaços com os quais os ciganos estabelecem diferentes relações independentemente do fato de não estar em seus nomes a área ocupada, daí considerase que 0 espaço geográfico dos ciganos na cidade forma um território.

O Território Cigano em Ipameri tem formas espaciais específicas, as quais julga-se elaboradas de acordo com a realidade sócio-cultural do grupo e apresentam características bem definidas, que garantem segurança, conforto e liberdade aos ciganos. A seguir algumas características da organização interna do Território. 


\section{A Organização espacial interna do Território Cigano em Ipameri}

Os critérios utilizados para a divisão e ocupação da área foram determinados pelo número de famílias constituídas em 1999. As duplas ocupações existentes em três lotes ocorrem devido a filhos que se casaram após a divisão. Já os dois lotes sem construção pertencem a filhos que no momento da divisão moravam separados dos pais e atualmente moram com os mesmos.

A área é servida de rede de energia, iluminação pública e rede d'água. Observa-se a inexistência de pavimentação, meiofio, galerias pluviais, rede telefônica, rede de esgotos, varrição de ruas e de calçadas construídas.

O espaço que cada família tem como "seu" território varia entre $96 \mathrm{~m}^{2}$ e $240 \mathrm{~m}^{2}$, onde é erguida sua moradia, onde são lavados roupas e utensílios domésticos, depositados pequenos objetos além de sua utilização para o trato dos cavalos. Esse espaço apresenta-se com uma dada magnitude, que contém dentro de si práticas cotidianas, com uma organização apropriada ao grupo para atender a sua funcionalidade sócio-cultural e econômica.

O cavalo sempre esteve presente na vida dos ciganos de Ipameri, e o comércio do animal é a principal atividade econômica da comunidade. A carroça puxada pelo cavalo é o meio de transporte utilizado pelos ciganos. Assim, dentre os espaços presentes no território, um deles é exclusivo do cavalo. Cada família deixa uma área reservada para a alimentação e cuidados com os animais durante o dia, haja vista que à noite os cavalos são "soltos" em um lote de propriedade particular, próximo ao território.

A organização das barracas e casas segue um mesmo princípio, baseado na hierarquia das famílias que tem como base o grau de poder de cada cigano perante 0 grupo, sua idade cronológica e 0 grau de intimidade entre as famílias, além das necessidades individuais e familiares.

Os mais velhos, Sr. José (atual líder) e sua esposa, moram no considerado "primeiro lote", com uma área um pouco maior que a dos outros lotes, com a maior área edificada $\left(69 \mathrm{~m}^{2}\right)$ e com a construção de um dos dois únicos banheiros construídos no local. São eles que normalmente fazem o contato entre todos os ciganos. No caso dos não ciganos, são os que primeiro recebem os visitantes informando aos demais quem são e o que querem os estranhos que chegam ao Território.

É importante frisar que o líder, também denominado "chefe", tem também como função mediar situações de conflito entre os membros do Território. O líder Sr. José Soares tem habilidade para falar e talento diplomático para estabelecer alianças. Quase o tempo todo ele está preocupado em ser 0 porta-voz do desejo da comunidade como um todo, o que pode ser observado em seu depoimento.

(...) os que estão nas barracas a situação tá difícil, onte eu fui lá no Prefeito, eu pedi ele, e ele me deu um rolo de prástico. 0 Prefeito, eu sou de dentro da cozinha dele. Eu vou chegano e entrano. Eu falei pra ele do prástico, ele perguntou um rolo dá, eu falei dá. Ele falou, eu levo amanhã.

Ele mesmo troxe aqui na minha porta (08/03/2003).

O líder tem prestígio e é ouvido geralmente com mais consideração do que os demais, tanto pelos ciganos quanto com a maioria dos não-ciganos que mantêm contatos. Porém, a organização cigana, em cada lote do Território, não é um quadro estático, imposto, comum a todos. Nos limites da sua área, as famílias expressam seus modos de vida, suas representações e particularidades. As casas, barracas e condições financeiras, demonstram a necessidade, o tempo e a identidade de cada família, através da organização interna das moradias ciganas.

\section{O significado da terra para os ciganos: introduzindo suas representações}

Além da terra significar para os ciganos um instrumento de fixação e os limites do Território, uma base térrea, um espaço apropriado e dividido e um local de reprodução cultural das famílias ciganas, a terra ocupada assume também um significado subjetivo do mundo vivido, cheio de perspectivas e representações.

Desde a sua constituição, o Território Cigano foi se transformando num lugar prenhe de história e de experiências de vida, através de suas relações sociais. Hoje é um local onde 0 cigano criou raízes e sentimentos afetivos, sentindo-se pertencente a ele. As relações estabelecidas com o lugar fazem com que as famílias se identifiquem com o mesmo.

0 valor atribuído ao território modifica-se de um cigano para 0 outro. Cada cigano identifica e filtra as informações do espaço de maneira única. 0 significado da terra para os ciganos pode até ser semelhante, porém para cada um deles o conteúdo desse significado possui uma particularidade.

O Território Cigano é percebido de maneiras diversas devido, principalmente, à sua heterogeneidade etária. Para as crianças e adolescentes, o lugar significa um palco de total 
liberdade, no qual, brincando e interagindo com a natureza elas desfrutam das regalias do mundo infantil; já os adultos vêem 0 agrupamento como uma extensão das relações que têm com a cidade de Ipameri, um espaço conhecido que já faz parte de seu território. Para os idosos, o lugar representa uma experiência de vida acumulada. Porém, para todas as faixas etárias e ambos os sexos, o Território Cigano em Ipameri significa um espaço de trocas culturais e de histórias distintas de vida.

O significado do território para os ciganos é, sobretudo, um lugar propício às suas sobrevivências. Indagados sobre 0 "porquê" de estarem no local, as respostas são quase unânimes: uma vida melhor. Assim, a terra se torna a segurança.

Constantemente o território cigano torna-se um lugar imaginário, um espaço construído no imaginário das famílias e que já possui um valor afetivo. As famílias criam expectativas da forma como seria o agrupamento nos próximos anos.

A imaginação sobre as suas novas moradias e os benefícios que esperam receber no território são fatores que sustentam a relação de afetividade com um lugar que poderá ser concretizado.

Daqui algum ano não vai ter ninguém na barraca. Deus vai ajudar que não. Hoje a gente prefere a casa. Nóis não vai sair mais daqui. A gente não importa mais com a vida passada, nóis quer esquecer tudo aquilo, quer trazer nada, naquela época era tudo custoso, hoje tudo é mais fácil (Zélia, 36 anos - 23/01/2003).

A concepção do Território Cigano em Ipameri como um lugar imaginário se revela nas palavras dos ciganos. As expectativas elaboradas com o lugar são expressas:

(...) Essa casa eu ganhei prontinha, desse jeito, eles me deram assim. As coisas é difícil, mas Deus dá um jeito. Deus ajuda. Daqui um tempo meus fios vão ter suas casa. Os que estão nas barracas a situação tá difícil, mas vai melhorar se Deus quiser, o povo daqui é muito bão pra nóis (José, 62 anos 08/01/2003).

Gosto de ficá aqui, aqui é bão. Gosto daqui. Aqui gosto de brincar (Lucas, 6 anos - 23/01/2003).

Como já foi salientado, a identidade do Território Cigano em Ipameri é uma somatória das representações simbólicas dos ciganos e das relações estabelecidas entre eles e os não ciganos. A cidade de Ipameri é um espaço com o qual os ciganos estabelecem diferentes relações.

\section{Considerações Finais}

Descrever, compreender, analisar, enfim, pesquisar sobre o Território Cigano em Ipameri possibilitou um olhar e um diálogo aguçado sobre a Geografia Cultural e a sua pertinência para 0 estudo da diversidade cultural.

Esse diálogo permitiu visualizar as diferentes referências de identidades construídas pelos variados segmentos étnicos no espaço, e ajudou compreender o papel preponderante que a cultura produzida por grupos sociais assume na Geografia. Sendo a organização espacial da sociedade marcada por fatores políticos, econômicos, sociais e culturais a Geografia, enquanto ciência social, visa também o estudo dos elementos culturais e deve ter um posicionamento diante da realidade de vários grupos étnicos.

Assim, acredita-se que o movimento da Geografia em direção às temáticas culturais aponta, entre outros, para a constatação de se conhecerem os significados específicos, construídos por cada grupo social no espaço.

Paul CLAVAL (1997) destaca que a orientação cultural na Geografia deve compreender como os grupos sociais constroem 0 mundo, a sociedade e a natureza. Essa orientação cultural deve se interessar pela maneira como são estabelecidos critérios que separam os grupos sociais. Para o autor, essa reflexão conduz a privilegiar, no mundo atual, como objetos geográficos da pesquisa cultural, grupos raciais e grupos étnicos.

Diante do diálogo exposto sobre a Geografia Cultural e seu referencial para a diversidade cultural, percebe-se que 0 espaço ocupado por cada cigano e demais seres humanos no mundo, pode ser percebido como o espaço da vida e é o símbolo daquele tipo de vida que o situa em relação a outras possibilidades. Isso permite dizer que esse espaço específico, que abriga a vida, assume a condição de espaço único e humanizado, na medida em que a representação elaborada pelas pessoas que ocupam este espaço se concretiza em representações espaciais.

O território cigano foi concebido através de sua específica funcionalidade, que abriga um potencial ilimitado de significações sociais, as quais definiram os chamados espaços simbólicos. Além de sua funcionalidade, a dimensão territorial constitui e organiza resistência ou aceitação, que foram capazes de criar uma identidade territorial e servir como ponto de convergência de interesses evidenciando a diversidade de dimensões que tem 0 território.

A pesquisa comprovou que a produção do Território Cigano em Ipameri, encarado aqui como resultante de um conjunto de relações sociais, é incessante e ininterrupta; não é algo acabado, 
mas está em contínuo movimento. 0 movimento de construção do território jamais terminará, especialmente porque se considera que a produção do território é fruto da existência humana.

Pôde-se compreender que a partir das relações sociais, 0 grupo cigano não só transforma o seu território, como também se modifica nesse processo. Os ciganos então foram considerados como elementos produtores de seu território. Os costumes e tradições dos ciganos não se mantêm intactos, mas são vivenciados cotidianamente pelos membros do grupo, e sofrem influências e transformações. É, portanto, sobre a própria idéia de aceitação e de resistência cultural que serão feitas as discussões finais do texto.

0 processo de sedentarização não é o único fator responsável pela aceitação/resistência dos ciganos na sociedade envolvente. Este processo sempre se deu parcialmente. A prática do nomadismo está enraizada no cigano, tornando-se comum algumas famílias saírem do território temporariamente a fim de exercerem atividades em outras localidades, principalmente quando seu território não Ihes garante condições econômicas para sobrevivência.

Os mecanismos de aceitação e resistência, em maior ou menor escala, são encontrados tanto em ciganos como nos demais moradores. Entre os ciganos, a aceitação reflete-se na adoção de valores e rituais da sociedade envolvente, porém, existe a pratica de atividades até certo ponto diferenciadas das concepções econômicas da sociedade majoritária, mesmo sem serem totalmente aceitas pelos ipamerinos.

Os ipamerinos através da rejeição, da estigmatização e da discriminação dos ciganos, levam muitas vezes os ciganos a adotarem uma postura dupla. Os ciganos aceitam apenas alguns traços culturais da sociedade não cigana e procuram sempre manter a coesão do grupo, baseada na sua específica organização social, econômica e cultural, através de suas relações sociais internas. Portanto, o processo de interação social entre 0 cigano e 0 ipamerino, passa pela barreira da imagem generalizada que se tem dos ciganos.

A análise geográfica da comunidade cigana em Ipameri possibilitou apreender a espacialidade desse grupo cigano, além de constatar a estreita relação de tal comunidade com o espaço e, portanto, as relações sociais, econômicas e culturais existentes no território, entre os ciganos. Além disso, o estudo desta comunidade trouxe à tona a questão das relações étnicas entre os ciganos e demais moradores de Ipameri.

Essa investigação traz como contribuição a compreensão da formação e estruturação de um território cigano no espaço urbano em Ipameri, o que, por sua vez, contribuiu para que a territorialização de tal comunidade seja reconhecida e considerada pelos demais moradores da cidade.

Outrossim, é preciso dizer que a cultura dos ciganos não pode ser desconsiderada pelos demais moradores, e que é necessário que se entenda essa cultura enquanto diferente e não enquanto inferior, para que seja mais valorizada, tanto pelos gestores públicos quanto pela população ipamerina. A história dessa comunidade cigana está presente em Ipameri e, de forma mais visível, a partir dos anos de 1980, nas barracas, nas vestimentas, nas festas e nas atividades comerciais do cavalo. Essa memória histórica precisa ser valorizada, recuperada e preservada. 
VAZ, A.D. (2007). The geography and its pertinence in the study of cultural diversity - a gypsy territory. Revista do Departamento de Geografia, n. 19, p. 69-80.

\begin{abstract}
In the last decades Geography opens new avenues on issues related to the partner-cultural processes such as the construction of identity, the cultural livings, the different ways of being and acting that several social groups build in the space. This article presents a dialogue on Cultural Geography and its relationship to the cultural diversity, focusing a study accomplished with a Gypsy Community in Ipameri, Southeast of Goiás. The main goal is to understand the different elements that constitute the formation of a territory and the process of formation by the group in the town. The reading of that reality from the point of view of the Cultural Geography and its working methods were the methodological approaches used in the development of this research.
\end{abstract}

Keywords: Geography; Cultural diversity; Gypsy; Territory.

Recebido em 21 de junho de 2005, aceito em 15 de dezembro de 2005.

\section{Referências}

ANDRADE, M. C. de (1994) Territorialidades, desterritorialidades, novas territorialidades: os limites do poder nacional e do poder local. In: SANTOS, M. (Org.) et al. Território Globalização e Fragmentação. São Paulo. Hucitec, p. 213220.

BUTTIMER, A. (1982) Aprendendo o Dinamismo do Mundo vivido. In: CHRISTOFOLLETTI, Antônio. Perspectiva da Geografia. São Paulo. Difel, p. 165-193.

CARA, R. B. (1994) Territorialidade e Identidade Regional no Sul da Província de Buenos Aires. In: SANTOS, M. (Org.) et al. Território - Globalização e Fragmentação. Tradução de Antônio de Pádua Danesi. São Paulo. Hucitec, p. 261-269.

CLAVAL, P. (1997) As abordagens da Geografia Cultural. Tradução de Paulo Cesar da Costa Gomes. In: CASTRO, I. E. de (Org.). Explorações Geográficas. Rio de Janeiro. Bertrand Brasil, p. 89-118.

(1999) A geografia Cultural. Tradução: Luiz Fuggazzola Pimenta e Margareth de Castro A. Pimenta. Florianópolis-SC, Editora da UFSC.

FERREIRA, A. M. (1999) Urbanização e Arquitetura na Região da Estrada de Ferro Goiás - E.F. Goiás: cidade de Pires do Rio, um exemplar em estudo. (Dissertação de Mestrado). Goiânia. UFG.

GOMES, P. C. C. (1996) Geografia e modernidade. Rio de Janeiro, Bertrand Brasil.

(1999) Culturas Teóricas, Culturas Políticas no Pensamento Geográfico. In: CASTRO, I. E. (Org.) et al. Redescobrindo o Brasil: 500 anos depois. Rio de Janeiro, Bertrand Brasil, p.
335-339.

HAESBAERT, R. (1995) Desterritorialização: Entre as redes e os aglomerados de Exclusão. In: CASTRO, Iná Elias de ( Org ) et al. Geografia: Conceitos e Temas. Rio de Janeiro. Bertrand Brasil, p. 165-205.

(1999) Identidades Territoriais. In: ROSENDALL, Z. L. (org.) et al. Manifestações da Cultura no Espaço. Rio de Janeiro, ED-UERJ, p. 169-189. (2002)Territórios Alternativos. São Paulo, Ed. Contexto.

HALL, S. (1992) A Identidade Cultural na Pós-modernidade. Rio de Janeiro, DP e A Ed, 1997. Tradução de Tomaz T. da Silva e Guaracira L. Louro. Título Original: The question of cultural identity, 1992.

LIMA, S. T. (2000) Paisagens e Ciganos. UNESP, tese-doutorado em Geografia, 1996. MORAES, Antônio Carlos R. Bases da formação territorial do Brasil. São Paulo, Ed. Hucitec.

RAFFESTIN, C. (1980) Por uma Geografia do Poder.Tradução de Maria Cecília França. São Paulo, Ática, 1993. Título original: Pour une geographie du pouvoir, 1980.

RATTS, A. J. P. (2000) 0 mundo é grande e a nação também: identidade e mobilidade em territórios negros. Tesedoutorado, USP, FFLCH, 2000.

RATZEL, F. (1990) As Raças Humanas. In: MORAES, Antônio Carlos Robert. (Org.) Ratzel. São Paulo, Ática, 1990, [1882/1891], p. 108-150.

Lê Sol, la Societê et l'etat. In: Annés Sociologique. $3^{\mathrm{a}}$ edición. Paris, 1987

SANTOS, V. R. (2002) Espacialidade e territorialidade dos grupos ciganos na cidade de São Paulo. Dissertação-Mestrado, 
USP, FFLCH, 2002.

SOUZA, M. J. L. (1995) O território: sobre espaço e poder autonomia e desenvolvimento. In: CASTRO, Iná Elias de. et al. Geografia: conceitos e temas. Rio de Janeiro, Ed.
Bertrand Brasil, p. 77-116.

TEIXEIRA, R. C. (1998) A questão cigana: uma introdução. Correrias de ciganos pelo território mineiro. DissertaçãoMestrado em História, Belo Horizonte, UFMG, 1998. 